Article

\title{
Bark Assortments of Scots Pine and Norway Spruce as Industrial Feedstock for Tall Oil Production
}

\author{
Mehrdad Arshadi * (iD, Daniel Eriksson, Patrik Isacsson and Urban Bergsten \\ Department of Forest Biomaterials and Technology, Swedish University of Agricultural Sciences, \\ SE-901 83 Umeå, Sweden; erikssondanie19@gmail.com (D.E.); patrik.isacsson@ahlstrom-munksjo.com (P.I.); \\ Urban.Bergsten@slu.se (U.B.) \\ * Correspondence: mehrdad.arshadi@slu.se; Tel.: +46-70-611-7884
}

Received: 26 April 2018; Accepted: 4 June 2018; Published: 6 June 2018

\begin{abstract}
Fatty and resin acids in bark residues generated by forest industries can be used to produce high-value green chemicals, but more information about their concentrations in potential sources is required. We examined variations in the content of lipophilic extractives from both pulpwood bark and timber bark of Norway spruce and Scots pine trees growing in homogenous stands in mid-Sweden. We found that spruce pulpwood bark had the highest total amounts of fatty and resin acids (average yield, $0.9 \mathrm{~kg} / \mathrm{m}^{3}$ wood). The regression functions, based on readily available tree parameters (age, stem diameter, height, growth rate and inner bark proportions), can be used to predict the concentrations of fatty and resin acids, triglycerides, sterols and steryl esters in bark materials before harvesting stands that supply industrial plants.
\end{abstract}

Keywords: fatty and resin acids; Picea abies (L.) H. Karst.; Pinus sylvestris L.; triglycerides; sterols; steryl esters

\section{Introduction}

Tall oil is a by-product of softwood Kraft pulping (sulphate process), which is widely used as a raw material for fuels and chemicals [1]. The main constituents of tall oil are fatty and resin acids (ca 90\%), which are sold (following fractionation by distillation) as pure tall oil fatty acids and tall oil rosin (or resin acids), respectively.

Bark from both of the two main softwood species, Fennoscandia, Scots pine (Pinus sylvestris L.) and Norway spruce (Picea abies L. Karst.), is commonly used to produce heat at mills or nearby power plants. However, it contains relatively high amounts of fatty and resin acids [2,3]. Thus, it is financially more promising to use bark extractives to produce tall oil. Bark is preferably not processed in alkaline (Kraft) pulping together with wood, as, e.g., its content of other extractives increases the consumption of alkali, harming rather than contributing to pulp production. Instead, isolated bark may proceed along a separate production line, designed for the production of chemicals from low-cost extractive rich tree fractions, by applying, e.g., supercritical $\mathrm{CO}_{2}$ extractions [4]. A complicating factor is that the chemical profiles of the bark varies between the two species [2,3,5-7], between individuals of the same species and between parts of individual trees. Notably, bark from timber and pulpwood logs may have differing proportions of inner (phloem) and outer (periderm) fractions due to differences in their diameters and numbers of annual rings [8], which significantly affect the chemical composition and structure of bark [7,9]. For example, Jyske et al. [10] found substantial variations in the content of stilbene glucosides in bark, both along trunks of individual Norway spruce trees and among different age groups. Thus, to optimize the exploitation of bark to produce green chemicals, it is essential to map key constituents (particularly fatty and resin acid contents) in bark assortments. 
With the aim of improving the use of Scots pine and Norway spruce bark, the objective of the present study was to map variations in its content of lipophilic extractives in relation to measured tree parameters and assortments obtained in thinning and final felling operations.

\section{Materials and Methods}

Bark samples were collected in October 2015 from three trees in each of two pine and two spruce single-layered monoculture stands with average productivities of $5.9-6.2 \mathrm{~m}^{3} \mathrm{ha}^{-1}$ year ${ }^{-1}$ in the district of Delsbo, mid-Sweden. One pine and one spruce stand were in the final cutting phase. The trees were 90-93 and 111-117 years old, with basal area $33 \mathrm{~m}^{2} \mathrm{ha}^{-1}$ and $35 \mathrm{~m}^{2} \mathrm{ha}^{-1}$, tree heights of $22.5 \mathrm{~m}$ and $21.4 \mathrm{~m}$, densities of 681 and 867 stems per hectare and total stem volumes of 408 and $354 \mathrm{~m}^{3}$ on bark (o.b.), respectively. The other pine and spruce stands were 45-48 years old (typical ages for thinning), with basal area-weighted tree heights of 11.5 and $11.3 \mathrm{~m}$, densities of 1840 and 1984 stems per hectare and total stem volumes of 172 and $167 \mathrm{~m}^{3}$ o.b. ha ${ }^{-1}$, respectively. Chosen trees were felled using a chainsaw. The cuts were labelled with a marker and photographed. The trees were cut at three positions: P1, P2 and P3. P1 were cut at breast height, $\mathrm{P} 2$ at the height of $\mathrm{P} 1+1 / 3 \mathrm{X}$ and $\mathrm{P} 3$ at the height of $\mathrm{P} 1+2 / 3 \mathrm{X}$.

The trees selected for sampling had similar sizes, canopy heights (defining a tree's canopy base as its lowest green branch) and ages to their neighbouring trees. Stem sections $1-2 \mathrm{dm}$ thick were taken from each selected tree at three heights: $1.3 \mathrm{~m}$, and at one third and two thirds of the distance between $1.3 \mathrm{~m}$ from the ground and the top. The diameter o.b. at each position was measured with a calliper ( $1 \mathrm{~mm}$ precision) before cutting, and the cross-sections of the samples were photographed together with a small calliper $(0.1 \mathrm{~mm}$ precision) using Digimizer version 4.6 .1 image analysis software to determine the number of annual rings, thickness of inner (phloem) and outer (periderm) bark, and average width of rings from the last 10 years [11]. According to a local pricelist, timber and pulpwood were defined at the sampling time and place as having a diameter under bark (u.b.) $\leq 140 \mathrm{~mm}$ and $>140 \mathrm{~mm}$, respectively.

The stem sections were debarked with a knife. Definitions and measurements of inner and outer bark, the method to isolate bark samples and the methodology for characterising bark in trees based upon measurements of stem sections are in accordance with earlier studies [8]. Three $10 \mathrm{~g}$ pieces of bark from each section (for density analysis and chemical analyses) were placed in separate labelled plastic bags, sealed with tape and stored in a cool-box with ice packs to minimize autoxidation [12]. At the end of each sampling day, bark samples for chemical analyses were put in a freezer $\left(-18^{\circ} \mathrm{C}\right)$. Subsamples that were not used for chemical analyses were oven-dried $\left(105^{\circ} \mathrm{C}\right)$ overnight to determine their dry weight and then re-soaked in water to measure their green volume, by the water displacement method, using a scaler with $0.01 \mathrm{~g}$ precision, allowing the density of the bark samples to be determined.

Bark materials from two sampled trees from each stand were chosen for chemical analyses, in which their content of lipophilic extractives were measured according to a modified standard [13]. Briefly, the samples were dried at $40{ }^{\circ} \mathrm{C}$ and then subjected to Soxhlet extraction with cyclohexane and acetone $(9: 1 v / v \%)$. The solvents were evaporated after extraction. The extracts were analysed by gas chromatography with the short column, HP1 capillary column from Agilent Technologies (5 m long, thin film $0.15 \mu \mathrm{m}$, wide bore $0.53 \mathrm{~mm}$ ), following a technique developed at Åbo Academy [14] for measuring concentrations of five groups of lipophilic extractives (fatty acids, resin acids, triglycerides, sterols and steryl esters) rather than single chemical species. In addition, the total concentration of lipophilic extractives in the samples were measured by summing all peaks in the gas chromatographs, including the so-called non-identified chemical species (compounds other than the five groups of lipophilic extractives). The internal standards, Heneicosanoic acid and Cholesteryl heptadecanoate, 1,3-Dipalmitoyl-2-oleoylglycerol, were used to quantify fatty and resin acids, steryl esters, triglycerides, and compounds in the samples [14].

The ratio between bark mass and wood volume at each sampling point was calculated from the basic density of the corresponding bark sample, stem diameter and bark thickness. The content of tall 
oil in bark per unit volume of wood was then calculated by multiplying the detected concentrations of extractives in bark by the corresponding bark mass to wood volume ratio. The results from the concentration and content of extractives calculations, sampling measurements, chemical analysis and basic density measurements were analysed with regression and variance analysis in MiniTab 17 [15], setting a significance threshold of $p \leq 0.05$ in all tests.

Both free and triglyceride-bound fatty acids were categorised as fatty acids in the statistical analysis. The sum of fatty and resin acids was named tall oil in the statistical analysis, and the difference between the total content of extractives and the content of identified extractives was attributed to other lipophilic extractives, which were called non-identified.

\section{Results}

There was no significant difference in basic density between the pine timber and pulpwood bark (308 and $307 \mathrm{~g} \mathrm{dm}^{-3}$, respectively). However, spruce timber bark had a higher basic density $\left(358 \mathrm{~g} \mathrm{dm}^{-3}\right)$ than spruce pulpwood bark $\left(329 \mathrm{~g} \mathrm{dm}^{-3}\right)$, and (in both cases) a significantly higher basic density than the pine bark.

The bark of the spruce pulpwood assortment had a significantly higher content of tall oil per unit volume of solid wood than the bark of the other assortments (Table 1). In both species, fatty and resin acid concentrations were higher in pulpwood bark than in timber bark. Concentrations of sterols and steryl esters were low relative to those of other extractives. Spruce bark had higher levels of resin acids but lower levels of fatty acids and sterols than pine bark. Levels of steryl esters did not differ much between the bark materials, and concentrations of other lipophilic compounds, except that of fatty and resin acids, triglycerides, steryl esters, and sterols, were similar in all samples (mean 3.54\%, standard deviation $0.48 \%$ ).

The correlations between the tree parameters and spruce bark concentrations of fatty and resin acids (and hence tall oil concentrations) ranged from moderate to strong (Figure 1).

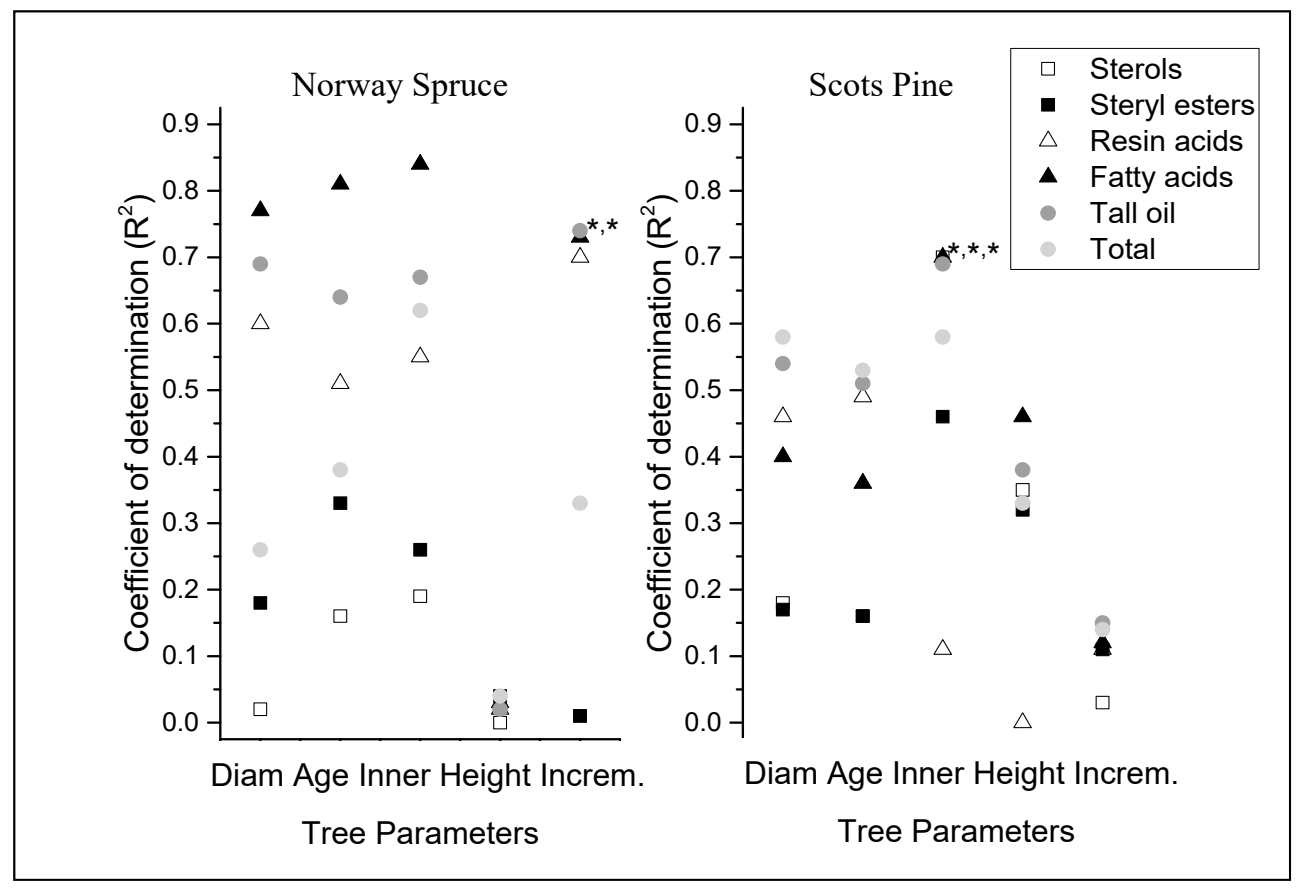

Figure 1. Coefficients of determination (indicating accuracy of predictions) from linear regression analysis based on the measured tree parameters for content of extractive compounds in Norway spruce and Scots pine bark samples. Diam, stem diameter; Age, number of annual rings; Inner, inner bark proportion; Height, sampling height in trees; and Increm., average annual ring increment in the last 10 years. ${ }^{*}$ significant parameter $(p \leq 0.05)$. 
Table 1. The concentrations in dry weight of identified and other lipophilic extractives in bark, and the content of tall oil in bark per unit volume of wood from forestry assortments. Different letters after the values denote significant differences ( $p \leq 0.05$, according to Analysis of Variance (ANOVA) with Tukey grouping) between bark sources. The number of samples was 8 for spruce timber, 4 for spruce pulpwood, 9 for pine timber and 3 for pine pulpwood.

\begin{tabular}{lcccccc}
\hline Assortments & $\begin{array}{c}\text { Resin Acids } \\
\mathbf{( \% )}\end{array}$ & $\begin{array}{c}\text { Fatty Acids } \\
\mathbf{( \% )}\end{array}$ & $\begin{array}{c}\text { Sterols } \\
\mathbf{( \% )}\end{array}$ & $\begin{array}{c}\text { Steryl Esters } \\
\mathbf{( \% )}\end{array}$ & $\begin{array}{c}\text { Other } \\
\text { Lipophilic } \\
\text { Compound (\%) }\end{array}$ & $\begin{array}{c}\text { Tall Oil per } \\
\text { Unit Wood } \\
\text { (g m }^{-3} \text { u.b.) }\end{array}$ \\
\hline Spruce & & & & & & \\
-pulpwood & $2.45^{\mathrm{A}}$ & 1.53 & $0.07^{\mathrm{A}}$ & 0.15 & 3.21 & $900^{\mathrm{A}}$ \\
-timber & $1.01^{\mathrm{B}}$ & 0.77 & $0.06^{\mathrm{A}}$ & 0.15 & 3.82 & $250^{\mathrm{B}}$ \\
\hline Pine & & & & & & \\
-pulpwood & $0.73^{\mathrm{BC}}$ & 2.05 & $0.18^{\mathrm{B}}$ & 0.21 & 4.00 & $215^{\mathrm{B}}$ \\
-timber & $0.17^{\mathrm{C}}$ & 1.23 & $0.16^{\mathrm{B}}$ & 0.17 & 3.31 & $125^{\mathrm{B}}$ \\
\hline
\end{tabular}

The inner bark proportion also correlated moderately with the total concentrations of lipophilic extractives. Similar but weaker correlations were found between the already-mentioned tree parameters and extractive content in pine, except that there was a weak but significant correlation between the sampling height and fatty acids. Correlations were very weak between the annual ring increment and extractive content, as well as between the concentrations of resin acids and inner bark proportion. In addition, very weak correlations were found between all tree parameters (except the inner bark proportion in pine) and the concentrations of sterols and steryl esters in the bark of both tree species.

\section{Discussion}

Detected content of the analysed extractives in bark from the tested assortments are within previously reported ranges for Norway spruce and Scots pine $[2,3,5,6]$. However, some of the lipophilic extractives were not identified. These may include polymerized and/or oxidized fatty and resin acids $[12,16]$, implying that the concentrations may have been underestimated. Variations in the yield of tall oil from the bark attached to logs can generally be attributed to variations in its concentration in the bark, but variations in the quantity of bark relative to wood also play a part. Thus, higher yields from pulpwood than from timber in spruce (as observed in this study) are partly due to similarities in bark thicknesses at different heights, while, conversely, Scots pines develop thick bark in their basal regions as an adaptation to forest fires [8].

Higher concentrations of lipophilic extractives were found in pulpwood bark than in timber bark, but the coincidence of the assortments, with overlapping locations within the green canopy, complicates the interpretation of this relationship. Further, the extractive content fitted well with regressions of the tree parameters, but their negative correlations with age and diameter, and positive correlations with inner bark proportion, height in trees and annual ring width are strongly interdependent and the sampling size is small. Nevertheless, the regression results are consistent with the growth rate effects on bark chemistry reported by Villari et al. [17] and comparisons between inner bark and outer bark by Ånäs et al. [7]. In contradistinction, Zavala et al. [18] found that contents of defence compounds like resin acids and terpenoids are inversely related to the growth rates of plants. However, the parameters most strongly correlated with defence compounds were not consistent in the two species. In both species, the measured tree parameter that was most strongly correlated with fatty acid content was the inner bark proportion. This is consistent with expectations, given this tissue's nutrient storage and transport functions, and hence its correlations with growth. Accordingly, the main differences between inner and outer bark in the study by Ånäs et al. [7] were in the content of fatty acids in Scots pine, whose content of resin acids contradicted that in Norway spruce. The total amount of fatty and resin acids in timber bark was about $1.5 \%$ of dry weight, which is in accordance with previous work [7]. It should be noted that contents of steryl esters and sterols have particularly weak and inconsistent 
correlations with tree parameters in spruce, but also a particularly small variation. The stronger correlations in pine, compared to spruce, are in accordance with the greater differences between inner bark and outer bark in pine found by Ånäs et al. [7]. However, the correlation may be more obvious and robust by increasing the number of analyses of samples with larger variations.

The freshness of the bark is one important aspect to bear in mind when applying an industrial perspective to the result, since extractives transform or decompose during storage [12,16]. The bark of this study was fresh when analysed; however, in reality, the bark would not be as fresh when it is debarked at the industry.

\section{Conclusions}

Spruce pulpwood is the most promising assortment for processing to acquire bark extractives as sources of tall oil or its main constituents. Thus, the potentially produced tall oil mass from bark in an area can now be calculated using pulpwood and timber volume data. The results also show that concentrations of targeted extractives in industrial bark feedstocks can be modelled pre-harvest using readily available tree parameters.

Further research can focus on bark residues of spruce at pulp mills, especially on logs originating from sites with high productivity.

Due to the variety of bark quality (freshness, source, etc.) challenges and perspectives, several methodologies (logistic issues, integration in the present processes, storage issues) are needed to address in a holistic way this sustainability transition of the bark from being a waste product to being a valuable product.

This article highlights the innovative methods, case and tool for promoting bark waste valorisation, and provides greater opportunity for the emerging bio economic aspects.

Author Contributions: U.B. (Funding Acquisition, concept, idea and writing), D.E. (Methodology, statistical calculations, validations and writing), P.I. for practical works with the materials, M.A. (Project administration, supervision, evaluation of data, original draft preparation and funding Acquisition).

Funding: The Authors would like to acknowledge financial support from FORMAS (the Swedish Research Council) for CETEX project. Financial support from to Holmen Forest Industry Group Acknowledged.

Acknowledgments: The authors would like to address special thanks to Holmen Forest Industry Group and in particular, Jörg Brücher for the recognition of this project idea, the work, the produced materials, and some data of the project.

Conflicts of Interest: The authors declare no conflict of interest.

\section{References}

1. Biermann, C.J. Essentials of Pulping and Papermaking; Academic Press: San Diego, CA, USA, 1993; p. 472.

2. Valentín, L.; Kluczek-Turpeinen, B.; Willför, S.; Hemming, J.; Hatakka, A.; Steffen, K.; Tuomela, M. Scots pine (Pinus sylvestris) bark composition and degradation by fungi: Potential substrate for bioremediation. Bioresour. Technol. 2010, 101, 2203-2209. [CrossRef] [PubMed]

3. Krogell, J.; Holmbom, B.; Pranovich, A.; Hemming, J.; Willför, S. Extraction and chemical characterization of Norway soruce inner and outer bark. Nord. Pulp Pap. Res. J. 2012, 27, 6-17. [CrossRef]

4. Attard, T.M.; Arshadi, M.; Nilsson, C.; Budarin, V.L.; Valencia-Reyes, E.; Clark, J.H.; Hunt, A.J. Impact of supercritical extraction on solid fuel wood pellet properties and off-gassing during storage. Green Chem. 2016, 18, 2682-2690. [CrossRef]

5. Norin, T.; Winell, B. Extractives from the bark of common spruce, Picea abies L. Karst. Acta Chem. Scand. 1972, 26, 2289-2296. [CrossRef]

6. Norin, T.; Winell, B. Extractives from the bark of scots pine, Pinus silvestris L. Acta Chem. Scand. 1972, 26, 2297-2304. [CrossRef]

7. Ånäs, E.; Ekman, R.; Holmbom, B. Composition of non-polar extractives in bark of Norway spruce and scots pine. J. Wood Chem. Technol. 1983, 3, 119-130. [CrossRef] 
8. Eberhardt, T.L. Longleaf pine inner bark and outer bark thicknesses: Measurement and relevance. South. J. Appl. For. 2013, 37, 177-180. [CrossRef]

9. Eberhardt, T.L. Impact of industrial source on the chemical composition of loblolly pine bark. For. Prod. J. 2012, 62, 516-519. [CrossRef]

10. Jyske, T.; Laakso, T.; Latva-Mäenpää, H.; Tapanila, T.; Saranpää, P. Yield of stilbene glucosides from the bark of young and old norway spruce stems. Biomass Bioenerg. 2014, 71, 216-227. [CrossRef]

11. Medcalc Software. Digimizer Free Image Analysis Software. 2015. Available online: http:/ /www.digimizer. com/ (accessed on 26 April 2018).

12. Nielsen, N.P.K.; Nørgaard, L.; Strobel, B.W.; Felby, C. Effect of storage on extractives from particle surfaces of softwood and hardwood raw materials for wood pellets. Eur. J. Wood Wood Prod. 2009, 67, 19. [CrossRef]

13. Scandinavian Pulp, Paper and Board Testing Committee (SCAN). Content of Extractable Lipophilic Matter; Scandinavian Pulp, Paper and Board Testing Committee: Stockholm, Sweden, 2003; Available online: http:/ / www.pulpandpaperservices.com/standards.html (accessed on 26 April 2018).

14. Örså, F.; Holmbom, B. A convenient method for the determination of wood extractives in papermaking process waters and effluents. J. Pulp. Pap. Sci. 1994, 20, J361-J365.

15. Minitab Inc. Minitab Statistical Software. 2016. Available online: https://www.minitab.com/en-us/ products/minitab / (accessed on 26 April 2018).

16. Sithole, B.; Lapierre, L.; Watanabe, C. A study of polymerization of aspen (Populus) wood lipophilic extractives by SEC and Py-GC/MS. Appita J. J. Tech. Assoc. Aust. N. Z. Pulp Pap. Ind. 2013, 66, 59-65.

17. Villari, C.; Faccoli, M.; Battisti, A.; Bonello, P.; Marini, L. Testing phenotypic trade-offs in the chemical defence strategy of scots pine under growth-limiting field conditions. Tree Physiol. 2014, 34, 919-930. [CrossRef] [PubMed]

18. Zavala, J.A.; Casteel, C.L.; DeLucia, E.H.; Berenbaum, M.R. Anthropogenic increase in carbon dioxide compromises plant defense against invasive insects. Proc. Natl. Acad. Sci. USA 2008, 105, 5129-5133. [CrossRef] [PubMed]

(C) 2018 by the authors. Licensee MDPI, Basel, Switzerland. This article is an open access article distributed under the terms and conditions of the Creative Commons Attribution (CC BY) license (http://creativecommons.org/licenses/by/4.0/). 